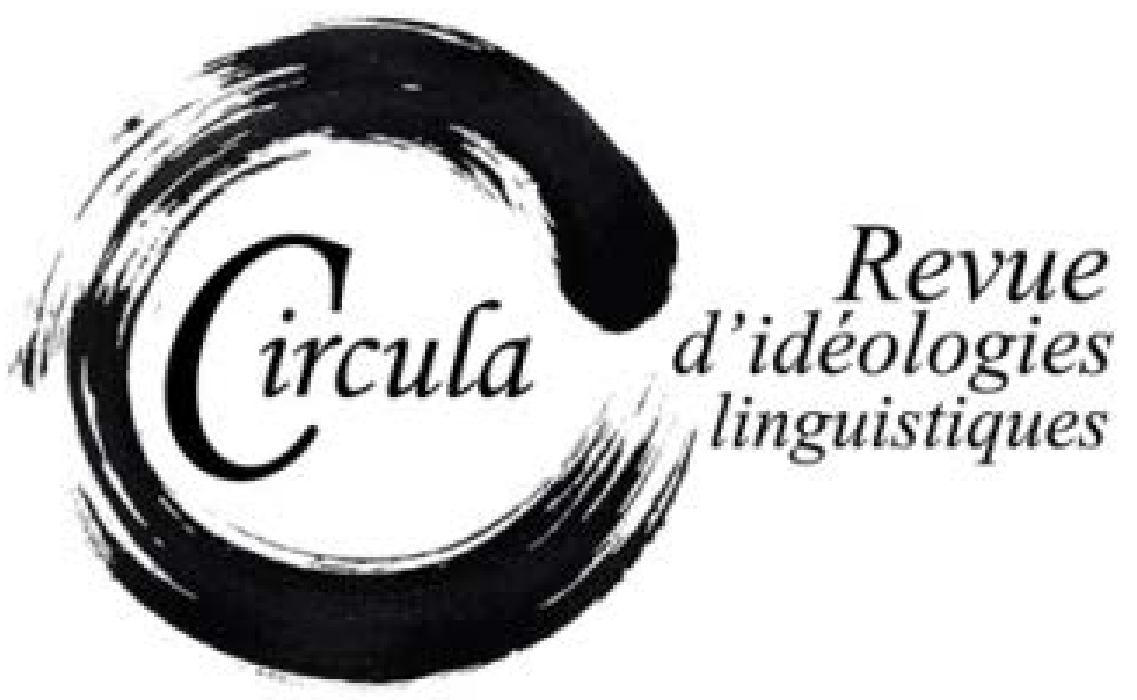

TItre: El Diario ESPAÑol Y EL DEBATE SOBRE LA ENSEÑANZA DEL CASTELLANO EN LA ARGENTINA (1927-1928) Auteur(s): Esteban Lidgett, Universidad de Buenos Aires-CONICET

Revue: Circula, numÉRO 1, PAGES 69-86

ISSN: 2369-6761

DiRecteurs: Wim REMYSEn et SABINE SCHWARZE

URI: HTTP://HDL.HANDLE.NET/11143/7991

DOI: $10.17118 / 11143 / 7991$ 


\section{El Diario Español y el debate sobre la enseñanza del castellano en la Argentina (1927-1928)}

Esteban Lidgett, Universidad de Buenos Aires-CONICET elidgett@ conicet.gov.ar

Resumen: Hacia 1927, El Diario Español publica una serie de entrevistas a distintas personalidades del ámbito intelectual y educativo argentino (entre los que se cuentan a Arturo Costa Álvarez, Eleuterio Tiscornia, Enrique García Velloso, José María Monner Sans y Juan Bautista Selva) sobre la enseñanza de la lengua en la Argentina y su vínculo con la Real Academia Española. En este trabajo proponemos examinar este suceso como parte de los debates ideológicos lingüísticos en los que se enfrentan distintas posiciones en torno a la necesidad de constituir una cultura "homogéneamente monoglósica" (Blommaert y Verschueren, 1998). Sostenemos, por lo tanto, que esta discusión que se desarrolla en el ámbito de un periódico de la colectividad española y que enfrenta a un conjunto de intelectuales, políticos y educadores pone de manifiesto un aspecto central del diálogo cultural entre España y Argentina: la cuestión del idioma.

Palabras clave: gramática escolar; ideologías lingüísticas; lengua nacional

Abstract: By 1927, El Diario Español published a series of interviews with various personalities of the Argentine intellectual and educational fields (among whom were counted Costa Arturo Alvarez, Eleuterio Tiscornia, Enrique García Velloso, José María Monner Sans and Juan Bautista Forest) about Spanish teaching in Argentina and its link with the Real Academia Española. We propose to consider this event as part of the ideological-linguistic debate in which different positions on the need to establish a "homogeneously monoglossic" culture are confronted (Blommaert and Verschueren, 1998). We hold, therefore, that this discussion, which took place in the context of a Spanish community newspaper, and confronted a group of intellectuals, politicians and educators, reveals a central issue of the cultural dialogue between Spain and Argentina: the language question.

Keywords: school grammar; language ideologies; national language 


\section{Introducción}

Durante las últimas décadas del siglo XIX y las primeras del XX, la Argentina experimenta, como consecuencia del proceso de formación y modernización del Estado nacional, un conflicto en torno a la definición de una identidad cultural sustentada en la lengua (Alfón, 2011; Toscano y García, 2011; Glozman y Lauría, 2012). Se trata de una serie de debates que se manifiestan también en otros espacios del universo hispanohablante, como consecuencia de los procesos de emancipación del siglo XIX, y que una parte de la crítica ha decidido calificar como debates ideológicos-lingüísticos (Ludwig, 1995; del Valle y Stheeman, 2002; Ennis, 2008). Dicha calificación es deudora de una conceptualización acerca de los vínculos entre lingüística e ideología, inicialmente propuesta por Woolard y Schieffelin (1994) y Woolard (1998) y continuada más tarde por Blommaert (1999) y Kroskrity (2000), que propone investigar los discursos sobre la lengua con especial énfasis en la influencia que estos ejercen sobre aquella.

En esta línea, se define a los debates como ideológicos en tanto se los considera como factores extra lingüísticos que ponen de relieve distintas formas de representación acerca de la lengua y su inscripción en una cultura nacional y que cumplen un papel mediador entre las representaciones sociales y los modos de hablar. En ese sentido, también se los considera lingüísticos, no solo porque se articulan alrededor de una idea de lengua nacional considerada como objeto central para la definición de la identidad cultural, sino también porque en virtud de su intervención sobre los modos de hablar pueden constituirse en agentes del cambio lingüístico. Estos debates se presentan de diversas formas y reconocen diferentes agentes que van desde el ámbito político institucional y académico hasta los intelectuales y la prensa.

En el caso particular de la Argentina, la prensa de las colectividades españolas, si bien ha sido poco explorada por la crítica, representa un espacio institucional de relevancia a la hora de identificar los distintos agentes implicados en el debate sobre la lengua. En ese sentido, como sostiene García Sebastiani (2004: 527), "la prensa de los emigrantes españoles asentados en Buenos Aires constituye uno de los espacios privilegiados para analizar los lugares de encuentro, de intercambio, de transferencia de ideas y de ensayos políticos que se estaban produciendo en su país de origen".

A comienzos del siglo XX, El Diario Español, principal órgano de prensa de la comunidad ibérica, ocupaba un lugar destacado dentro del público porteño. Entre los diferentes tópicos que atravesaron sus páginas, la cuestión de la lengua no se mantuvo ausente. En efecto, entre diciembre de 1927 y enero de 1928, El Diario Español se hace eco de una polémica en torno al lugar que debía ocupar la Gramática de la Real Academia Española (GRAE) en la enseñanza del idioma en la Argentina. El periódico de la colectividad española publica una serie de entrevistas y editoriales en los que participan, además del ministro de instrucción pública de la Nación, distintas personalidades del mundo intelectual ligadas al ámbito de la filología, las letras y la educación. La polémica pone de manifiesto no sólo la relevancia que por entonces asumía la cuestión de la lengua en el ámbito público local, 
sino también la posición que asume El Diario Español en los debates sobre la lengua nacional como instrumento de difusión de imágenes y representaciones sobre la identidad nacional en general y el idioma en particular.

El corpus está constituido por cinco notas editoriales y seis entrevistas a distintas personalidades del ámbito lingüístico, todas publicadas en El Diario Español entre el 18 de diciembre de 1927 y el 8 de enero de 1928. El propósito de este trabajo es examinar en este corpus las distintas posiciones en juego acerca del rol de la Real Academia Española (RAE) en la educación local; y, en términos más amplios, los supuestos que se ponen de manifiesto con relación a la definición de la lengua nacional. Dichas posiciones y supuestos, si bien se esgrimen en torno a una problemática específica, permitirán analizar la constitución de El Diario Español como un agente que participa de manera activa en el debate ideológico-lingüístico, asumiendo una postura que promueve la creación de una Academia correspondiente en Argentina. Esta postura puede ser analizada a partir de una operación discursiva que tiende a definir un modelo de identidad nacional sustentado en una cultura monoglósica.

\section{Los debates ideológico-lingüísticos: una aproximación teórica}

Los debates ideológico-lingüísticos en el mundo hispanohablante reconocen una diversidad de tópicos conforme el momento histórico y la región específica en la que se los analice. Si la expansión colonial española había conseguido establecer una hispanofonía (Ludwig, 1995) sustentada en una supracultura hegemónica, las distintas naciones emergentes americanas no tardarán en poner en confrontación aquella supracultura con sus identidades nacionales emergentes. Como señala Ennis (2008) siguiendo a Ludwig (1995), un interrogante fundamental para comprender en términos generales la cuestión de la lengua en las nuevas naciones americanas es el siguiente:

[...] si España percibe la lengua como símbolo de una cultura nacional, fundada a su vez en un canon literario, y a la vez eleva ésta en el proceso de expansión colonial al rango de una "supracultura", ¿qué espacio de acción queda a las nuevas naciones, a las colonias independizadas, para la construcción de la propia identidad y así para el diseño de los símbolos culturales necesarios para ello? (Ennis, 2008: 14)

El punto de partida de la cuestión de la lengua es, entonces, el conflicto que se desarrolla en el siglo XIX, momento en cual las naciones latinoamericanas deben constituir su propia identidad cultural y, al mismo tiempo, España sufre una fuerte crisis identitaria motivada por la pérdida de las colonias. En ese contexto surge el "hispanismo", que encuentra su materialización más palpable en la organización de diferentes congresos, simposios y publicaciones, así como en la creación de las diversas Academias correspondientes de la lengua ya avanzado el siglo XIX.

1. A partir de los años 70 del siglo XIX comienzan a crearse academias de la lengua en distintos países de Hispanoamérica. Se trata de organismos oficiales que comenzaron a funcionar progresivamente durante el siglo XIX en países como 
Según del Valle y Stheeman (2002), el hispanismo se basa en el supuesto de que existen una cultura, un estilo de vida, una tradición y unos valores única y característicamente españoles; de modo que, para esta concepción, como postula Ennis (2008: 21), la cultura hispanoamericana "no sería nada más que la misma cultura española transplantada al nuevo mundo".

Así planteada, la cuestión de la lengua parece subsumirse en una contradicción de identidades nacionales entre España y sus excolonias. No obstante, los debates ideológico-lingüísticos que se desarrollan en la hispanofonía, si bien de alguna manera encuentran su origen en la cuestión nacional, distan mucho de ser meramente un enfrentamiento entre intereses nacionales independentistas y colonialistas. La complejidad de estos debates está dada, precisamente, por la variedad de los agentes que se constituyen como sujetos en ellos.

En ese sentido, como señalan del Valle y Stheeman (2002), los diversos proyectos de construcción de comunidades llevados a cabo en el mundo hispánico en los últimos dos siglos se caracterizan por estar fundados sobre un mismo sustento ideológico-lingüístico: el de la cultura monoglósica (del Valley Stheeman, 2002: 193). La cultura de la monoglosia es definida como un conjunto relativamente abstracto de creencias acerca de conceptos generales como lengua, habla, comunidad lingüística y lectoescritura (del Valle y Stheeman, 2002: 10). Esta cultura de la monoglosia se caracteriza sobre todo por dos principios fundamentales: el principio de focalización y el principio de convergencia. Según el primero, hablar una lengua exige el conocimiento de una gramática, entendida como un sistema invariable y preciso, mientras que todo lo que diverge de este sistema, o que está sometido a un alto grado de variación es objeto de estigmatización. El segundo (el principio de convergencia) designa la concepción según la cual toda comunidad tiende a volverse progresivamente homogénea, eliminando de su seno las anomalías estigmatizadas.

En esta línea, la idea de cultura monoglósica es sustancial para comprender el desarrollo de los debates ideológicos-lingüísticos sobre todo hacia fines del siglo XIX y principios del XX. En particular, consideramos que constituye un marco de referencia ineludible para analizar el contexto en el que se lleva a cabo la intervención de El Diario Español en la polémica acerca del rol de la RAE en la enseñanza del idioma.

Colombia, Ecuador, México, El Salvador, Venezuela, Chile, Perú y Guatemala. El vínculo entre estas Academias y la RAE se realizaba a través de la designación de miembros correspondientes en los distintos países. En la Argentina, la cuestión de la creación de una Academia correspondiente hacia la década del 70 provocó reacciones adversas entre los posibles miembros locales. Mientras Bartolomé Mitre, Vicente Fidel López, Ángel Justiniano Carranza, Luis Domínguez, Carlos Guido Spano, Vicente Quesada, Pastor Obligado, Ernesto Quesada y Carlos María Ocantos aceptaron su designación como correspondientes, Juan María Gutiérrez se opuso y envió su rechazo a tal designación en diciembre de 1875. Más tarde, en 1910, tras la visita de la Infanta Isabel en el marco de la celebración por el primer Centenario, se funda en Buenos Aires la Academia Argentina de la Lengua, correspondiente de la RAE, bajo la dirección de Vicente Quesada. Sin embargo, esta asociación fue diluyéndose en los años sucesivos y no logró establecer vínculos con el resto de las academias de Hispanoamérica. Será recién en 1931 cuando se funde la Academia Argentina de Letras por decreto oficial. 


\section{El Diario Español como agente en el debate sobre la lengua en la Argentina: la controversia sobre la RAE}

Durante las primeras décadas del siglo XX se incrementó de manera notable el intercambio cultural entre España y Argentina. En ese sentido, la prensa de los emigrantes españoles en Argentina constituye un interesante ámbito para analizar el desarrollo del intercambio cultural entre ambos países.

El Diario Español, un importante órgano de difusión de esta comunidad, inició su tirada en 1905, bajo la dirección de Justo López de Gomara (1859-1923). Su antecedente inmediato puede hallarse en El Correo Español, publicación que se mantuvo desde 1872 hasta 1905 y que fue dirigida por el mismo López de Gomara entre 1880 y 1890. La colectividad española contaba hacia la segunda mitad del siglo XIX con algunas publicaciones importantes. El primer periódico de la comunidad se edita en 1852, cuando el madrileño Benito Hortelano (1819-1871), radicado en Buenos Aires desde 1850, funda El Español. También durante ese año aparece la Revista Española, destinada a la publicación de avisos concernientes a los inmigrantes ibéricos. Por su parte, en 1881 se publica el primer número de La Nación Española; ya entrado el siglo XX, aparecerán también en el país periódicos representantes de las distintas facciones de la política peninsular en el contexto de la Guerra Civil, como fueron La Falange Española o España Republicana.

En general, el rol fundamental de la prensa comunitaria consistió en otorgarle mayor injerencia en la opinión pública a determinados escritores, publicistas y emprendedores periodísticos extranjeros con el objetivo de que pudieran constituirse como interlocutores de la élite gobernante. En ese sentido, como señala García Sebastiani (2004: 527), El Diario Español se constituyó como un importante órgano de expresión pública y permitió "construir imágenes, identidades, representaciones de la colectividad emigrante española por encima de sus diferencias sociales, étnicas y políticas, constituyéndose como la voz de la colonia y forjador de opiniones concretas".

Entre diciembre de 1927 y enero de 1928, El Diario Español publica una serie de artículos referidos a la enseñanza del idioma en la Argentina. Los artículos, que incluyen editoriales de los responsables del diario y entrevistas a distintas personalidades del ámbito educativo e intelectual argentino, se escriben en respuesta a una controversia presuntamente ocurrida entre las autoridades de la RAE y el ministro de instrucción pública argentino, Antonio Sagarna, motivada por la aparente exclusión de la Gramática académica de los programas escolares. Este corpus, compuesto por cinco notas editoriales y seis entrevistas, constituye un singular testimonio del estado de situación del debate sobre la lengua hacia fines de la década del 20, pocos años antes de la fundación de la Academia Argentina de Letras en 1931. Al mismo tiempo, estos textos permiten observar de qué modo ingresa ese debate, no ya en el interior de la comunidad intelectual, académica y científica, sino en un medio de prensa destinado sobre todo a la comunidad española, pero también al público general. 
La controversia se inicia cuando, el 17 de diciembre de 1927, el diario argentino La Prensa registra en una nota, que envía como telegrama al periódico El Sol de Madrid, que el Ministerio de Instrucción Pública ha excluido a la Gramática académica como texto de referencia para los cursos de lengua en los colegios nacionales. Al día siguiente, El Sol se hace eco de esta información y publica un editorial con el título "La Academia Española en la Argentina”, en el que critica la supuesta medida adoptada por el gobierno argentino. El 18 de diciembre del mismo año, El Diario Español publica una nota titulada “Defensa de la gramática de la Academia española por un diario madrileño", en la que se limita a citar una parte del artículo de El Sol en la que se elogia la labor académica y se censura la actitud del ministro: "En el aspecto técnico del idioma - aspecto que desdeña el ministro argentino - es indiscutible la eficacia de la Academia Española”.

Tras la repercusión pública de este acontecimiento, El Diario Español emprende una serie de entrevistas en las que participan funcionarios, escritores y profesores del ámbito local (entre los que se cuenta a Antonio Sagarna [1874-1949], Arturo Costa Álvarez [1870-1929], Eleuterio Tiscornia [18791945], Enrique García Velloso [1880-1938], José María Monner Sans [1896-1987] y Marco Avellaneda [1868-1937]), quienes aportan sus consideraciones sobre la relación entre la Academia Española y la enseñanza del idioma en Argentina.

La primera entrevista a propósito del asunto es al Dr. Sagarna, ministro de instrucción pública del gobierno de Alvear. En la nota, publicada el 22 de diciembre de 1927, Sagarna declara taxativamente que no existía ningún decreto ni resolución ministerial que excluyera al texto académico de los colegios nacionales. El ministro se ocupa de explicar el procedimiento a través del cual la Comisión examinadora de textos, entidad que funcionaba desde la creación del Consejo Nacional de Educación en 1881, evaluaba las obras que se le presentaban. El procedimiento consistía en la conformación de un jurado de personas competentes que debían seleccionar, dentro de las obras que habían sido presentadas a concurso, aquellas que podían considerarse "obras exigibles" y las que debían ser consideradas "obras de consulta”. Las primeras tendrían el carácter de obligatorias en los colegios nacionales; las segundas, optativas.

Sagarna se defiende de las acusaciones que le formulara la prensa madrileña señalando que nadie había remitido la Gramática de la RAE para su evaluación en la Comisión, por lo que difícilmente se hubiera podido excluirla o aceptarla. Durante toda la entrevista el ministro se cuida de no formular juicio alguno sobre la Academia Española ni sobre la cuestión del idioma nacional; simplemente deposita toda explicación en el procedimiento burocrático de la Comisión revisora. El mismo día de la entrevista, El Diario Español también publica un editorial bajo el título: "Los textos para la enseñanza del castellano en el país", en el que se ocupa de orientar el eje de la discusión hacia el tema de la lengua nacional en Argentina. El editorialista (que no firma la nota) aclara la supuesta controversia apoyando las palabras de Sagarna y destacando el hispanismo del ministro, cuya cultura - sostiene - ha sido "informada en el más sano españolismo" (El Diario Español, 18 de diciembre de 1927). 
No obstante, lejos de zanjar la cuestión aquí, la nota intenta abrir el debate e identifica algunos de los tópicos centrales de la cuestión de la lengua, al señalar la importancia de abordar este tipo de problemáticas:

[...] serán pocos todos los esfuerzos que se hagan en ese sentido para atajar, y remediar en lo posible, las graves deficiencias que se notan en el empleo del castellano, mal hablado y peor escrito, como consecuencia de la abigarrada y multiforme inmigración que llega al país y de una deficiente enseñanza del idioma nacional. (El Diario Español, 18 de diciembre de 1927)

Resulta destacable que, en esta intervención, el problema de la relación de la Real Academia con el sistema educativo argentino se vea atravesado, más que por la cuestión hispanista o nacionalista, por la necesidad de depurar las deficiencias del idioma local. El problema de la lengua se subsume, en los editoriales del diario y en las opiniones de algunos de los entrevistados, a la cuestión de la depuración de un lenguaje cuya "corrupción" se muestra como consecuencia del aluvión inmigratorio.

En efecto, tras publicarse la entrevista en la que Sagarna sostenía que no había existido voluntad alguna de excluir el texto académico, El Diario Español publica una segunda nota editorial en la que destaca la extensa labor del ministro en pos de la conservación de la lengua española:

Son bien conocidos sus amores dilectos para que se haga el más perfeccionado empleo del idioma cervantino afianzando sus dominios lexicográficos en estas tierras argentinas, y así lo prueban importantes resoluciones que en este sentido adoptó y entre las que recordamos la creación de cátedras españolas de lectura y declamación de castellano y el mantenimiento de la prueba escrita en los exámenes del idioma. (El Diario Español, 22 de diciembre de 1927)

La controversia, en esta segunda nota editorial, ya no enfrenta al ministro de Instrucción Pública con la Real Academia, sino que el eje del debate pasa a ser la cuestión de la lengua en la Argentina y la necesidad de ceñirse a la autoridad académica como solución al problema de la corrupción lingüística.

En la siguiente entrevista, publicada el 23 de diciembre, José María Monner Sans, abogado y docente de la Facultad de Filosofía y Letras de la Universidad de Buenos Aires, sostiene la necesidad de adoptar la gramática académica como un "código para todos los que hablamos español". La posición de Monner Sans revela cierta despreocupación por la cuestión de la lengua porque, desde su óptica, al menos en el ámbito intelectual, a diferencia de lo que ocurría en épocas anteriores, ya no existirían voces partidarias de una lengua propia distinta del español peninsular:

[...] los sistemáticos y ciegos ataques a la Academia ya no están de moda [...]. En América cundió el virus porque así se aparentaba despreocupación [...] hasta que la moda nos hizo virar en redondo y, de diez años a esta parte, la mínima porción culta de nuestro país empieza a cuidar sus modos de expresión hablada. En la otra, en la máxima porción barbarizante, se codean el hombre que viste frac y el que gasta blusa: son los cultivadores del lunfardo y de 
la jerga al revés que, nacida entre la gente del hampa, se cuela hasta el taller, el periódico, la escuela, la banca, el comercio, el salón mundano, la poesía, etc. (El Diario Español, 23 de diciembre de 1927)

Las palabras de José María Monner Sans presentan la cuestión del idioma como un problema que finalmente ha sido desplazado de la intelligentzia nacional, luego de las múltiples reacciones que provocó el libro de Abeille a comienzos del siglo XX². Y si bien la cuestión estaba lejos de haberse zanjado hacia los años 20 y 30, el discurso de Monner Sans, en sintonía con la línea editorial del diario, pretende desplazar la temática hacia la cuestión de la corrupción lingüística y la necesidad de la codificación. En ese sentido, como se observa en la cita, el peligro de la corrupción lingüística sigue apareciendo como una amenaza que alcanza a todos los niveles de la sociedad, desde el "hombre que viste frac" hasta "el que gasta blusa".

Monner Sans finaliza su entrevista haciendo referencia a la modernización de la Academia española y a la necesidad de adoptar su Gramática como texto escolar:

No quiero concluir las declaraciones que me pide el Diario Español sin recalcar que don Ramón Menéndez Pidal - salido de las filas del disconformismo - está ahora al frente de la corporación madrileña. Algo parece haberse remozado la que "limpia, fija y da esplendor" [...]. Están allí, por lo menos, hombres de dos generaciones: la reposada, anterior al desastre colonial hispano y algunos representantes de la de 1898. No sería, pues, de buen gusto emprenderla contra la Academia, cuya Gramática, si se lleva al ministerio, habrá de ser lógicamente incorporada a nuestros libros habituales de enseñanza. (El Diario Español, 23 de diciembre de 1927)

La referencia a la renovación de la Academia española, que desde 1925 estaba a cargo de Ramón Menéndez Pidal, se presenta como un argumento a favor de la posibilidad y la necesidad de generar una confraternidad del mundo hispano que debía manifestarse en el ámbito de la lengua a partir de una codificación lingüística uniforme.

La siguiente entrevista se publica el 26 de diciembre y es Arturo Costa Álvarez, lingüista autodidacta, traductor y periodista, quien expresa su opinión sobre el tema. Costa Álvarez evita responder directamente a la cuestión de si la GRAE debe o no ser incluida como texto obligatorio. En cambio, se ocupa de hablar de la enseñanza del idioma en los colegios y de polemizar con lo que considera "el criterio de autoridad en la gramática". Sostiene que "esta gramática doctrinaria nos sume hasta el fondo en los principios dogmáticos y en los métodos formalistas del escolasticismo" y que es en

2. Nos referimos a Idioma nacional de los argentinos (1900), donde Lucien Abeille, en línea con el proyecto esbozado por el historicismo romántico decimonónico argentino (v. Oviedo 2005), expone su posición sobre la creación de una codificación lingüística particular e independiente del español peninsular. Sobre la recepción crítica y el rechazo que generó esta publicación entre buena parte de la intelectualidad local existe numerosa bibliografía: Costa Álvarez (1922), Rosenblat (1961), Rubione (1983), Oviedo (2005), Ennis (2008), Alfón (2011), Toscano y García (2011), entre otros. 
ese "atraso" donde hay que ver "la causa de su inutilidad y conveniencia". Frente a esto Costa Álvarez sostiene que:

[...] se impone un cambio de espíritu, de principio y de método; en cuanto a espíritu, no debe ser tradicionalista sino contemporánea, reconociendo que su objeto es mantener la unidad de la lengua en la evolución y no su invariabilidad a través del tiempo; en cuanto a principio, no debe ser preceptista, como un cuerpo de doctrinas o un manual de arte, sino demostrativa, como un catálogo de hechos; en cuanto a su método, no debe ser una obra de clasificación formal sino de organización ideológica que refiere las diversas formas de expresión a los correspondientes modos del pensamiento; y en cuanto a su materia, debe ceñirse a la lengua actual y a su uso práctico, sin entrometerse en las investigaciones del lingüista sobre su origen y la evolución de las formas. (El Diario Español, 26 de diciembre de 1927)

La postura de Costa Álvarez retoma los postulados de artículos previos como "La neogramática del castellano" (1925) y “La enseñanza de la gramática” (1928), donde se planteaba la necesidad de reemplazar los métodos de enseñanza y la concepción tradicional de la gramática. En ese sentido, considera fundamental que se reemplace el "criterio de autoridad" por el de "mejor uso actual" y "que se eliminen las definiciones mnemónicas", "porque en esta materia práctica, la memoria debe aplicarse a la retención de los hechos solamente" (El Diario Español, 26 de diciembre de 1927). La posición de Costa Álvarez en rechazo de la codificación lingüística según el criterio de autoridad de la Academia debe vincularse con su propio posicionamiento frente a la reforma de la enseñanza de la gramática en la Argentina. En efecto, Costa Álvarez inicia en los años 20 una enérgica campaña para consolidar un renovado proyecto de enseñanza de la lingüística; un proyecto que finalmente alcanza a consolidarse, aunque con una orientación muy distinta de la que proponía Costa Álvarez, tras la gestión de Amado Alonso en el Instituto de Lingüística (v. Toscano y García, 2011; Lidgett, 2013; Toscano y García, Battista y Lidgett, 2013).

De esta forma, en la entrevista a Costa Álvarez, aunque no se mencione a la Academia española, se manifiesta un rechazo por la regulación lingüística en el sentido en el que la planteaba, por ejemplo, José María Monner Sans; y, por otro lado, se postula la necesidad de una reforma integral en los contenidos y los métodos de la enseñanza gramatical.

El dramaturgo y criollista Enrique García Velloso, por su parte, en la entrevista publicada el 27 de diciembre, sí hace expresa su crítica hacia las autoridades de la Real Academia; en primer lugar, por no haberse ocupado de que la GRAE atravesara los carriles que la ley nacional había promovido y, en segundo lugar, por haber desatendido a los miembros correspondientes de la Argentina, Ernesto Quesada (1858-1934), Marco Avellaneda y Calixto Oyuela (1857-1935). En ese sentido, propone que se debe "ampliar el número de académicos correspondientes en la República” y atender más a la labor de los estudiosos locales. 
García Velloso critica los ataques de la prensa española a Sagarna y se ocupa de defender la obra del ministro, quien - sostiene - "es uno de los que más intensamente y más extensamente se han preocupado de ordenar el aprendizaje y depuración del castellano en la República Argentina”. Asimismo, en relación con la cuestión del idioma en este país, sostiene que "ningún país del mundo necesita preocuparse tanto como el nuestro del aprendizaje de su idioma; y dentro de nuestro país, ninguna ciudad como la de Buenos Aires". Más adelante, agrega:

Son la escuela elemental, el colegio secundario y el conservatorio las instituciones que pueden dar unidad espiritual y alma nacional a los componentes infinitamente diversos de los más diversos hogares de la República; y es merced al idioma patrio, heredado de España, bien enseñado en su sintaxis y en su prosodia, que lograremos la necesaria fusión racial. (El Diario Español, 27 de diciembre de 1927)

La posición de García Velloso retoma aquella concepción decadentista de comienzos del siglo XX, que consideraba que el progreso material obtenido con la inmigración era la contracara de una decadencia cultural que debían combatir las leyes y la educación. De acuerdo con esta postura, el problema de la lengua debía solucionarse junto con los demás problemas sociales, y todos reconocían su origen en la heterogeneidad y el cosmopolitismo reinantes; una heterogeneidad de la que, como en la cita de Monner Sans, no están excluidos ni la literatura ni "los hombres que visten frac".

En la siguiente entrevista, publicada el 30 de diciembre, Marco Avellaneda, miembro correspondiente de la Academia, comienza por mencionar los precedentes de la "actual controversia lingüístico gramatical" en la Argentina. Tras una breve mención a su participación en el debate parlamentario de 1896 en torno a la obligatoriedad de la enseñanza del castellano en la instrucción elemental ${ }^{3}$, Avellaneda afirma que la GRAE debe ser "texto preferido por su reconocida autoridad" en el ámbito educativo.

En la misma línea que las intervenciones anteriores, aquí se vuelve sobre el problema del idioma y la necesidad de regulación por parte de la Academia. En ese sentido, Avellaneda defiende el rol institucional de la corporación académica descartando las acusaciones de conservadurismo elevadas por algunos intelectuales: "la Academia estaba y está abierta, sin vanos prejuicios, para acoger toda palabra que responda a una sentida necesidad del progreso y sea usada por una mayoría indiscutida”. No obstante, al igual que García Velloso, hace explícita una leve crítica a su funcionamiento:

3. En septiembre de 1894 el diputado conservador Indalecio Gómez presenta, ante la Comisión de Instrucción Pública, el Proyecto de ley relativo a la enseñanza en idioma nacional. En él se proponía la obligatoriedad del uso del idioma nacional en todas las escuelas del territorio nacional, con el objetivo de limitar la extensión de la enseñanza en lengua extranjera en la Argentina, en particular en las colonias extranjeras radicadas en el país. Aunque en esa oportunidad no llega a tratarse, en 1896 Gómez vuelve a presentarlo y el proyecto logra un despacho favorable fundamentado por Marco Avellaneda. Si bien no alcanzó los votos necesarios, el proyecto de ley impulsó un debate que se extendió durante tres jornadas, los días 4, 7 y 9 de septiembre de 1896. Para un estudio más amplio sobre este debate puede consultare Bertoni (2001) y Vázquez Villanueva (2006). 
Esa natural disposición en los académicos de número tendría aun mayor repercusión y reportaría todos los deseados beneficios si se llamasen los puestos aquí vacantes de miembros correspondientes, se mantuviesen con ellos activas relaciones que se traducirían en mejoras para los trabajos de "la que limpia, fija y dá esplendor", en relación a la natural evolución idiomática en estos países. (El Diario Español, 30 de diciembre de 1927)

En línea con estas observaciones críticas, El Diario Español publica, el 1 de enero de 1928, una nueva nota editorial titulada "Relaciones culturales hispano americanas", en la que retoma las críticas realizadas por García Velloso y Avellaneda respecto a la inacción de la Academia en América y sugiere a la corporación que realice las concesiones necesarias para intensificar las relaciones con la Argentina:

Indudablemente la acción de la Academia Española en la Argentina ha sido hasta ahora por demás deficiente limitada a la designación de varios miembros correspondientes, con los que luego no mantuvo activas relaciones [...].

No hemos de encarecer toda la trascendental importancia que para el porvenir del idioma en Sur América tiene la labor de los miembros correspondientes de la Academia en estos países, pues sin modificar el esencial carácter del castellano (y menos pretender la formación - imposible - de idiomas propios, en cada una de estas naciones) la vida iberoamericana impone voces y giros de forzosa aceptación y reconocimiento que, por responder a sentidas necesidades, por no chocar con al eufonía y por ser usados por gente culta e ilustrada deben agregarse, las unas, al acervo común de nuestra lengua, e influir sanamente, los otros, en los cánones gramaticales. (El Diario Español, 1 de enero de 1928)

A partir de esta nota, la línea editorial parece variar el foco de la controversia hacia un aspecto más general del debate acerca de la lengua en Hispanoamérica: ¿Cuál debe ser el rol de las academias correspondientes en la lucha contra la desintegración lingüística? De esta forma, frente al peligro constante de la babelización, la línea editorial de El Diario Español no duda en recomendar a la Academia aceptar las nuevas "voces y giros" que circulan en el habla culta de América, siempre que sea posible otorgar un marco de legitimación para el cambio lingüístico.

Asimismo, para contribuir con esa tarea de renovación del accionar de la Academia, el editorialista puntualiza la necesidad de que la "docta corporación" se ocupe más arduamente de la cuestión del idioma en la Argentina, "mediante la intensificación de las relaciones con sus miembros correspondientes y por la designación, en tal carácter, de personal de autoridad reconocida en materias gramaticales, para que así pueda constituirse la corporación filial argentina" (El Diario Español, 1 de enero de 1928). Finalmente, no debe resultar extraño que, hacia el final de la nota, el editorialista sugiera como posibles candidatos a miembros correspondientes los nombres de Costa Álvarez, García Velloso o el propio Sagarna, quienes por distintas razones habían exhibido sus críticas a la Academia. La necesidad de una codificación uniforme para contrarrestar el proceso de babelización creciente es considerada una prioridad tan acuciante que admite la suspensión de cualquier diferencia menor 
con respecto a cuestiones coyunturales y, asimismo, exige todas las concesiones necesarias para lograr el objetivo de una comunidad lingüística homogénea.

Finalmente, el último de los entrevistados es Eleuterio Tiscornia, escritor criollista, docente y vocal del Consejo Nacional de Educación. Tiscornia retoma la idea de la codificación lingüística, como la había planteado Monner Sans:

Es indiscutible que siendo la Gramática de la Academia [...] verdadero código gramatical, debe ser - como los son para otro orden de conocimientos o de relaciones sociales, los códigos civil y penal de cada pueblo - el libro base o fundamental en la enseñanza del idioma sin ningún trámite oficinesco. (El Diario Español, 3 de enero de 1928)

Para Tiscornia "el gran problema es el de la (sic) Unidad del idioma", una "finalidad que debemos perseguir con todo tesón, sin que tal Unidad vaya en contra de los matices peculiares a la expresión verbal de cada uno de estos pueblos". Para lograr ese objetivo es preciso que la enseñanza del idioma incorpore el texto académico como un código de referencia necesaria para todos los países de Hispanoamérica. Las "peculiaridades de la expresión verbal" que afloran en las distintas variedades del español en América, para Tiscornia no son elementos disolventes, siempre y cuando sea la autoridad académica la que los incorpore:

La gramática de la Academia es el resultado de la labor de hombres eminentes que, en representación de la Corporación han ido estatuyendo las reglas comunes a todos los que quieren emplear correctamente la lengua de Castilla; y son aquellos los que van modificándolas según las exigencias de los tiempos, si bien dentro, siempre, del espíritu tradicional o conservador en que deben inspirarse esa clase de trabajos. (El Diario Español, 3 de enero de 1928)

La posición de Tiscornia parece considerar el cambio lingüístico con cierta cautela: siempre que el origen de ese cambio esté aceptado y controlado por una corporación capaz de unificar y establecer el código lingüístico común y de velar por su conservación, la lengua puede variar. Y es precisamente esta, según el entrevistado, la tarea que viene llevando a cabo la Academia desde su fundación, cuando sus modelos gramaticales eran realizados "conforme a la construcción gramatical latina, la lengua madre". En los años sucesivos, fue "aligerándolos de esa tradición" e incorporando innovaciones que pasaron a constituirse como norma.

El debate sobre la incorporación del texto académico se cierra con dos notas editoriales, una a cargo de la redacción del diario y otra a cargo de José María Monner Sans. La primera, publicada el 6 de enero de 1928, exhibe una síntesis del debate en la que se celebra que la discusión haya sido útil para lograr una futura incorporación de la GRAE como texto obligatorio en la enseñanza nacional. En ese sentido, la línea editorial del diario manifiesta su satisfacción por "haber servido leal y correctamente los intereses instructivos argentinos y los de la política hispanoamericana" (El Diario Español, 6 de enero de 1928), puesto que 
Merced a [estas entrevistas], se ha despertado el olvido o desconocimiento de la Academia Española, que ha podido enterarse de las disposiciones legales aquí vigentes para la declaración de un libro cualquiera, como texto exigible a los alumnos; el interés de los entendidos por estas intrincadas cuestiones gramaticales; la importancia que todos, técnicos y profanos, asignan al conocimiento más perfecto del lenguaje que nos es común; la conveniencia de que la Academia llene los puestos vacantes, en el país, de académicos correspondientes, organizando la corporación filial y sus trabajos, en bien de la Gramática y del Diccionario; y esclarecido que en la supuesta exclusión nadie ha tenido "la voluntad preconcebida" de desconocer la autoridad del texto académico que debe ser declarado como exigible sin sujeción a formulismos, tal vez innecesarios. (El Diario Español, 6 de enero de 1928)

De esta forma, El Diario Español se posiciona como un agente que debe intervenir activamente en el intercambio cultural entre España y la Argentina, y que debe velar por la conservación de la unidad lingüística. El estrechamiento de los lazos con la Real Academia es un objetivo fundamental para esa tarea y la fundación de una filial local se considera un paso decisivo para ello.

Por su parte, la nota editorial de José María Monner Sans con la que se cierra el debate lleva por título: "Nuestra futura academia de la lengua". En este artículo, publicado el 8 de enero del 1928, Monner Sans revela un intercambio epistolar que su padre, el gramático Ricardo Monner Sans (1853-1927), había tenido con el académico José Alemany (1866-1934), en el que éste le solicitaba un informe de situación para que le explicara los motivos por los cuales no se instituía en la Argentina una Academia correspondiente. Ricardo Monner Sans responde que a su juicio "lo que más ha entorpecido el crecimiento de las Academias Americanas" es el hecho de que "los estatutos de la Real Academia dispongan, con el propósito de conceder autonomía a sus correspondientes, que sean éstas las que propongan el nombramiento de los futuros académicos". Esa situación de relativa autonomía habría desacreditado a las filiales locales y, al mismo tiempo, habría producido la falta de unidad que tanto se criticaba. De acuerdo con la nota de José María Monner Sans, Alemany remite una carta a Ricardo Monner Sans, fechada el 10 de marzo de 1927, en la que escribe: "Creo que esta vez se reorganizará esa filial y que ello en parte se deberá a usted cuya cartita leí dos veces en la comisión de gobierno de la Academia".

Tres años más tarde del debate que aquí seguimos, en 1931, la Academia Argentina de Letras se crearía en Buenos Aires, por decreto del gobierno dictatorial de José Félix Uriburu. Dicha Academia contemplará la promoción del estudio de la lengua y de la literatura y se asignará a sí misma en su Acta de Constitución la tarea de velar por la "conservación y pureza" de la lengua, a partir de la fuerte "convicción de que el idioma es un tesoro que debe ser cuidado y acrecentado para que las formas vivientes de nuestra cultura sean la expresión de una ponderable disciplina" (AAL, 1931). Los ideales de disciplina, conservación y pureza se condicen en esos inicios tanto con la tarea depuradora propia de este tipo de academias como con la aspiración de la ciudad letrada de constituirse en una comunidad homogéneamente monoglósica. 


\section{Conclusión}

La tarea de contribuir a la conformación de una comunidad homogéneamente monoglósica puede decirse que es un objetivo al que apuntan tanto el discurso de El Diario Español como las políticas educativas de las instituciones oficiales. En ese sentido, como sostiene Rubione (1983):

[...] se nacionalizó españolizando, pues la clase dirigente patricia que era en su mayoría de origen español, encontró en su pasado la vía para controlar el presente. De tal modo impusieron el idioma de su sangre. Por eso desecharon las propuestas argentinizantes, porque detrás de ellas podría sobrevenir Babel. [...] Hacia 1900 un sector numeroso de la clase dirigente ha terminado de invertir el modelo sarmientino. Ya hemos visto que lo preinmigratorio se consagra. Ser argentino es ser profundamente español y mantener intacta la lengua española, obra de argentinidad. (Rubione, 1983: 36)

La cita de Rubione expresa con claridad el advenimiento del hispanismo hacia comienzos del siglo XX como paradigma cultural dominante en un amplio sector de la intelectualidad argentina. En ese sentido, la percepción de la cuestión de la lengua como una dicotomía entre codificación monolingüe o fragmentación puede ser analizada como un rasgo característico, aunque no exclusivo, de esa cultura hispanista partidaria de una supracultura hegemónica.

En ese sentido, las intervenciones del diario a partir de los editoriales y las de los distintos entrevistados ponen de manifiesto ciertos tópicos comunes que caracterizan a la cuestión de la lengua a comienzos del siglo XX en Argentina. Como puede apreciarse en los textos aquí analizados, la idea de lengua nacional aparece como reflejo de una comunidad monoglósica (en los términos que antes definimos), cuya supervivencia depende de la capacidad de las instituciones (en particular, la escolar) para imponer el idioma patrio según una codificación uniforme. En línea con lo anterior, la confraternidad con España (y, en especial, con la institución académica) se reclama como un elemento necesario para contribuir a esta "batalla" contra la corrupción del idioma. Y la cuestión de la lengua queda subsumida, de esta forma, a la oposición entre una codificación monolingüe o el peligro de una fragmentación idiomática inexorable.

Sin embargo, aunque es posible encontrar un tópico común en las distintas intervenciones, que podría sintetizarse en lo expuesto más arriba, los entrevistados desarrollan distintos argumentos y diferentes conceptualizaciones en torno a la definición del problema de la lengua. Estas distinciones ponen en evidencia la complejidad de este tipo de debates y las diversas aristas que atraviesan la cuestión de la lengua, incluso cuando se la analiza en el marco de una cierta confraternidad de ideas.

La posición de Costa Álvarez (la única que se opone abiertamente a la intervención académica) desplaza el eje del debate hacia la propia incapacidad de los gramáticos de conformar un cuerpo de doctrinas actualizadas y sustentadas en descripciones científicas antes que en preceptos autoritarios. De este modo, la crítica de Costa Álvarez debe ser leída como un rechazo de la tradición 
gramatical escolar imperante en la Argentina durante las tres primeas décadas del siglo XX antes que como una abjuración de la "tradición de la queja", a la que el propio Costa Álvarez había contribuido notablemente en Nuestra lengua (1922). Probablemente esta misma lectura hacen los editorialistas de El Diario Español que recomiendan a Costa Álvarez como posible académico correspondiente.

Por su parte, en Monner Sans, García Velloso y Avellaneda puede verse una leve crítica al funcionamiento de la RAE en lo que respecta a su vínculo con los miembros correspondientes locales y su reticencia a la hora de incorporar nuevos giros lingüísticos. Sin embargo, estos tres entrevistados y también Tiscornia coinciden en señalar el cosmopolitismo como un problema para la lengua nacional y la codificación lingüística uniforme como una solución.

Por último, cabe mencionar las distintas intervenciones que realiza la redacción de El Diario Español, que va desplazando el eje del debate desde un tópico inicial, circunscrito en torno a la pregunta puntual sobre si la GRAE debía ser un texto de referencia para los cursos de gramática en la Argentina, hasta un tópico más amplio que incluye la necesidad de estrechar los lazos culturales entre España y la Argentina. En ese sentido, desde un planteo más general y abarcativo acerca del funcionamiento ideológico del rol de la prensa, resulta interesante analizar la pretensión de El Diario Español de constituirse en un agente intermediario en las relaciones culturales entre España y la Argentina para intervenir en la creación de una Academia correspondiente en este país. Ese objetivo de confraternidad lingüística monolingüe, expresado en el ideal de una institución reguladora capaz de detener la inevitable babelización, si bien, como hemos visto, no es asumido de manera uniforme por los entrevistados, sí es presentado por la línea editorial del diario como un objetivo concomitante.

4. Milroy y Milroy (1985) se han referido a la tradición de la queja para señalar una línea de pensamiento según la cual la lengua está siempre en decadencia. Adoptamos aquí la expresión, siguiendo a Di Tullio (2003) y Ennis (2008), para referirnos al discurso decadentista propio de la época (y estrechamente ligado al hispanismo) según el cual la lengua española en la Argentina se veía amenazada por la abundancia de usos no normativos en el lenguaje cotidiano. 


\section{Bibliografía}

\section{Fuentes primarias}

“Defensa de la gramática de la Academia española por un diario madrileño", El Diario Español, Buenos Aires, Argentina, 18 de diciembre de 1927, p. 14.

"Los textos para la enseñanza del castellano en el país", El Diario Español, Buenos Aires, Argentina, 18 de diciembre de 1927, p. 8.

"Nuestras entrevistas: la gramática de la Academia y la enseñanza del castellano. Entrevista con Antonio Sagarna", El Diario Español, Buenos Aires, Argentina, 22 de diciembre de 1927, p. 5-7.

"Nuestras entrevistas: la gramática de la Academia y la enseñanza del castellano. Entrevista con José María Monner Sans", El Diario Español, Buenos Aires, Argentina, 23 de diciembre de 1927, p. 8-10.

"Nuestras entrevistas: la gramática de la Academia y la enseñanza del castellano. Entrevista con Arturo Costa Álvarez", El Diario Español, Buenos Aires, Argentina, 26 de diciembre de 1927, p. 12-14.

"Nuestras entrevistas: la gramática de la Academia y la enseñanza del castellano. Entrevista con Enrique García Velloso", El Diario Español, Buenos Aires, Argentina, 27 de diciembre de 1927, p. 10-12.

"Nuestras entrevistas: la gramática de la Academia y la enseñanza del castellano. Entrevista con Marco Avellaneda", El Diario Español, Buenos Aires, Argentina, 30 de diciembre de 1927, p. 7-9.

"Relaciones culturales hispano americanas", El Diario Español, Buenos Aires, Argentina, 1 de enero de 1928, p. 5.

"Nuestras entrevistas: la gramática de la Academia y la enseñanza del castellano. Entrevista con Eleuterio Tiscornia", El Diario Español, Buenos Aires, Argentina, 3 de enero de 1928, p. 10.

“Explicación necesaria: la enseñanza del castellano y la Gramática de la Real Academia”, El Diario Español, Buenos Aires, Argentina, 6 de enero de 1928, p. 8.

Monner Sans, José María, "Nuestra futura Academia de la Lengua”, El Diario Español, Buenos Aires, Argentina, 8 de enero de 1928, p. 15.

\section{Fuentes secundarias}

AAL (Academia Argentina de Letras) (1931), Estatuto de la Academia Argentina de Letras, disponible en http://www.aal.edu.ar/?q=node/152. [Página consultada el 15 de junio 2013.]

Alfón, Fernando (2011), La querella de la lengua en Argentina (1828-1928), tesis doctoral inédita, La Plata, Universidad Nacional de La Plata. 
Bertoni, Lilia Ana (2001), Patriotas, cosmopolitas y nacionalistas: la construcción de la nacionalidad argentina a fines del siglo XIX, Buenos Aires, FCE.

Blommaert, Jan y Jef Verschueren (1998), "The Role of Language in European Nationalist Ideologies”, en Bambi Schieffelin, Kathryn Woolard y Paul Kroskrity (eds.), Language Ideologies: Practice and Theory, New York/Oxford, Oxford University Press.

Costa Álvarez, Arturo (1922), Nuestra lengua, Buenos Aires, Sociedad Editorial Argentina.

Blommaert, Jan (1999), Language Ideological Debates, Berlín/Nueva York, Mouton de Gruyter.

Costa Álvarez, Arturo (1925), "La neogramática del castellano”, Humanidades, nº X, p. 203-255.

Costa Álvarez, Arturo (1928), “La enseñanza de la gramática”, Humanidades, n XVIII, p. 151-176.

Del Valle, José y Luis Gabriel Stheeman (eds.) (2002), The Battle over Spanish between 1800 and 2000: Language Ideologies and Hispanic Intellectuals, Londres/Nueva York, Routledge.

Di Tullio, Ángela (2003), Políticas lingüísticas e inmigración: el caso argentino, Buenos Aires, Eudeba.

Ennis, Juan Antonio (2008), Decir la lengua: debates ideológico-lingüísticos en Argentina desde 1837, Fráncfort del Meno, Peter Lang.

García Sebastiani, Marcela (2004), "Crear identidades y proyectar políticas de España en la Argentina en tiempos de transformación del liberalismo: El Diario Español de Buenos Aires (1905-1912)", Estudios Migratorios Latinoamericanos, n55, Buenos Aires, 2004, p. 525-554.

Glozman, Mara y Daniela Lauria (2012), Voces y ecos: una antología de los debates sobre la lengua nacional (Argentina, 1900-2000), Buenos Aires, Cabiria/Ediciones Biblioteca Nacional.

Kroskrity, Paul (ed.) (2000), Regimes of Language: Ideologies, Polities and Identities, Santa Fe (e.o.), School of American Research Press.

Lidgett, Esteban (2013), "Apuntes sobre el problema de la lengua nacional en la gramática escolar argentina”, en Daniela Lauría y Mara Glozman (eds.), Lengua, historia y sociedad: apuntes desde diversas perspectivas de investigación lingüística, Buenos Aires/Mendoza, Sociedad Argentina de Lingüística/Editorial FfyL-UNCuyo, p. 33-43.

Ludwig, Ralph (1995), "Sprache als Kultursymbol", en Wolfgang Raible (ed.), Kulturelle Perspektiven auf Schrift und Schreibprozesse: elf Aufsätze zum Thema Mündlichkeit und Schriftlichkeit, Tubinga, Gunter Narr, p. 187-214.

Milroy, James y Lesley Milroy (1985), Authority in language: investigating language prescription and standardisation, Londres, Routledge \& Kegan Paul.

Oviedo, Gerardo (2005), "Luciano Abeille y el idioma nacional de los argentinos", en Lucien Abeille, Idioma nacional de los argentinos, Buenos Aires, Biblioteca Nacional/Colihue, p. 11-88.

Rosenblat, Ángel (1961), Las generaciones argentinas del siglo XIX frente al problema de la lengua, Buenos Aires, Instituto de Filología Hispánica "Dr. Amado Alonso". [1 ed.,1960.] 
Rubione, Alfredo (ed.) (1983), En torno al criollismo, Buenos Aires, Centro Editor de América Latina.

Toscano y García, Guillermo (2011), Amado Alonso en el debate acerca de la lengua nacional: el papel del Instituto de Filología de la Universidad de Buenos Aires en la redefinición del objeto (1923-1946), tesis doctoral inédita, Buenos Aires, Universidad de Buenos Aires.

Toscano y García, Guillermo, Emiliano Battista y Esteban Lidgett (2013), “Les archives d’Amado (18961952): correspondance et travaux inédits", en Valentina Chepiga y Estanislao Sofía (eds.), Archives et manuscrits de linguistes: études et état des lieux, Lieja, Academia-Bruylant.

Woolard, Kathryn A. (1998), "Introduction: Language Ideology as a Field of Inquiry", en Bambi B. Schieffelin, Kathryn Woolard y Paul Kroskrity (eds.), Language Ideologies: Practice and Theory, Nueva York/Oxford, Oxford University Press, p. 3-47.

Woolard, Kathryn y Bambi Schieffelin (1994), "Language ideology", Annual Review of Anthropology, $n^{\circ} 23$, p. 55-82.

Vázquez Villanueva, Graciana (2006), "Una política lingüística en el callejón: hacer la nación, unificar la lengua en Argentina (1890-1900)”, Lenguaje, n³4, p. 97-123. 